\title{
A COMPARATIVE THERMAL AND STRUCTURAL ANALYSIS OF DIFFERENT DISC BRAKE MATERIALS
}

\author{
UTKARSH GAHLAUT, PRIYESH GUPTA, RAGHAV AGNIHOTRI, \\ PURU MATHUR \& SANATAN RATNA \\ Mechanical Engineering Department, Amity University, Uttar Pradesh, India
}

\begin{abstract}
Disc brakes are presented to vast heat problems between routine braking and uncommon heat problems between hard braking. The point of the undertaking is to configuration, show a plate. Structure and Thermal investigation is to be done on the disc brakes utilizing three materials Aluminum Alloy, Gray Cast Iron and Stainless Steel. Basic examination is done on the plate brake to approve the quality of the disc brake and heat analysis is done to break down the heat properties. Examination should be possible for distortion; stresses, temperature and so forth frame the three materials to check which material is ideal.

Solidworks is a 3D displaying programming generally utilized as a part of the outline procedure. ANSYS is universally useful limited component investigation (FEA) programming bundle. Limited Element Analysis is a numerical technique for deconstructing a mind boggling framework into little pieces (of client assigned size) called elements.

KEYWORDS: Discbrakes, Routine Braking, Solidwork, ANSYS \& Limited Element Analysis
\end{abstract}

Received: Jul 11, 2018; Accepted: Aug 31, 2018; Published: Nov 8, 2018; Paper Id.: IJMPERDDEC201846

\section{INTRODUCTION}

It is an instrument which utilizes frictional capacity to constrain the development of a vehicle. The brake holds dynamic essentialness and releases it as heat imperativeness. Disc brake is a fundamental bit of vehicle deceleration structure. It is the kind of brake that utilizations calipers to push set of brake pads against a plate to reach. That contact coordinates the turn of a pole (vehicle focus point) to hold it stationary or coordinate its rotational speed. Disc brake is ordinarily made of solid metal or imaginative composite, for example Aluminum, cast press and stainless steel.

The disc brake is pounded between two cushions enacted by a chamber kept up in a caliper mounted on the stud shaft. At the point where the brake lever is pulverized, pressurized water controlled smashed liquid is obliged in the chamber pushing the invalidating barrels and brake parts. Precisely when the cushion is squeezed against the plate, the brake ingests motor centrality of the vehicle and it is moved into the hotter part which is by and large eaten up by rotor and brake cushion. This gleam is scattered into the joining air. In perspective of the season of frictional heat on the interface of the disc and cushion, there is moving in temperature. Precisely when this temperature beats the basic estimation of the given material, it prompts unfortunate occasions, for example, brake come up short, troublesome wear, and thwarted expectation of bearing, heat break or vaporization of brake liquid. Furthermore, because of heat age at the disc plate cushion interface, general bending happens in disc and cushion. Some normal miss happenings are coning and getting. Three sorts of mechanical pressure are subjected 
on disc brake.

- Traction power, caused by transmitting effect and it happens when wheel is pivoting and no brake compel is associated with the plate.

- Compressive power, when the brake is associated due to movement of the power, connected by pressing the pad inverse onto the surface of the plate.

- Due to braking movement caused by rubbing on the brake pad against the surface of the plate. It acts backward course of the disc plate pivot.

\section{MATERIALS USED}

- Gray Cast Iron: Gray cast iron, a composite of iron (Fe) and carbon (C), has picked up prominence in the market in light of the fact that of its minimal effort. It can construct composite structures. The measure of carbon in cast iron is $2-4.5 \%$ of its weight. It is neither pliable nor flexible, and it can't be solidified like steel. It dissolves at temperatures of around $2100-2190^{\circ} \mathrm{F}$, and has a crystalline or a granular fracture. Cast iron has an extensive variety of uses incorporating its use in hardware, cookware, funnels, auto parts, for example, barrel heads, squares, gearbox cases, and so on.

- Aluminum Alloy: It is the world's most rich metal and is the third most vital part including $8 \%$ of the world's outside. Aluminum is one of the lightest organizing metals, having a quality to weight degree superior to steel. Aluminum is most as frequently as conceivable alloyed with copper, zinc, magnesium, silicon, manganese and lithium. The heat conductivity of aluminum is around three times more basic than that of steel. This makes aluminum a key material for both cooling and heating applications, for instance, heat exchangers.. The determination of unadulterated aluminum is around $90 \mathrm{MPa}$ regardless this can be contacted in excess of 690 MPa for some glimmer treatable composites.

- Stainless Steel: It is one of the finest type of steel which has higher strength, corrosion resistance and are iron-based alloys that contain a minimum of around 10.5\% Chromium. Stainless steel also retains strength and shock resistance even at high temperatures. Therefore it is a appropriate choice for the manufacturing of brake discs. It has tensile strength of $505 \mathrm{MPa}$.

Table 1: Properties of Disc Brakematerials

\begin{tabular}{|l|c|c|c|}
\hline \multicolumn{1}{|c|}{ Properties } & Gray CastIron & StainlessSteel & Aluminumalloy \\
\hline Density (kg/m^3 ) & 7100 & 7750 & 2770 \\
\hline Young' s modulus (GPa) & 125 & 190 & 71 \\
\hline Poison' s ratio & 0.25 & 0.3 & 0.33 \\
\hline $\begin{array}{l}\text { Thermal conductivity (w/m- } \\
\text { k) }\end{array}$ & 54.5 & 26 & 190 \\
\hline Specificheat (j/kg-k) & 586 & 500 & 880 \\
\hline
\end{tabular}

\section{Software Used}

Solidworks can draw clear 3D drawings, it can demonstrate the cut procedure and can get virtual assembly. Solidworks is 3D windows-based CAD programming, which embraces parametric modeling strategies, has part modeling, assembly modeling and generations of 2D designing illustrations. It can make any complex shapes element effortlessly. 
It is one of the 3D programming software which is easy to use for beginners. ANSYS is universally used finite element analysis (FEA) software package. "FEA" is a numerical strategy for deconstructing a complex framework into little pieces called elements. It is a software which performs structural, thermal, and electromagnetic examinations. It can give optimal solution for the problem.

\section{Meshing of Disc}

Meshing of a component is done on ansys. It means to divide the component into number of elements for analysis. It isvery important during analysis as it divides the load uniformly to the elements. It is required to carry out finite element analysis. The elements used for the mesh of the model are tetrahedral three-dimensional elements with 8 nodes. A finite element mesh model generated is shown below

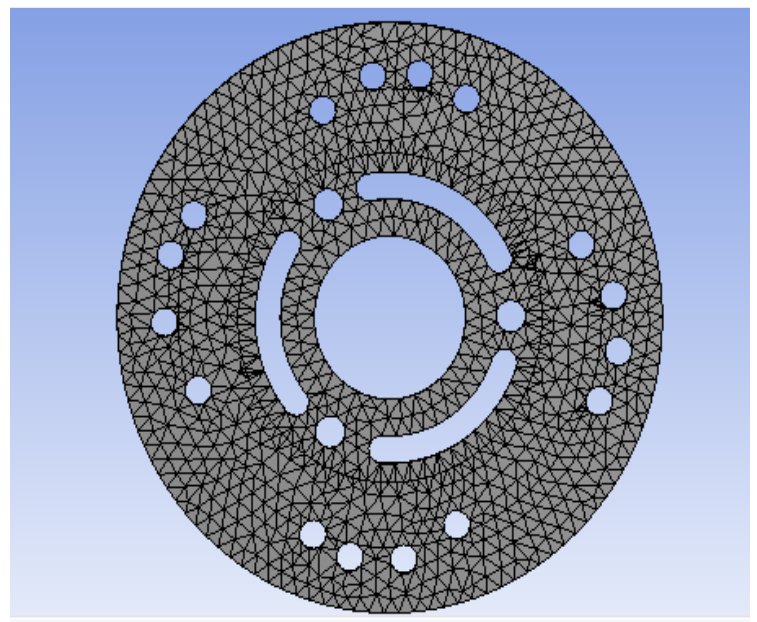

Figure 1: Meshing of Disc

The number of nodesis 17770 and the number of elementis 8989 .

\section{RESULTS AND DISCUSSION}

\section{Case 1:- Aluminium Alloy Brake Disc}

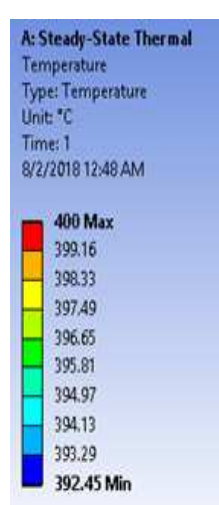

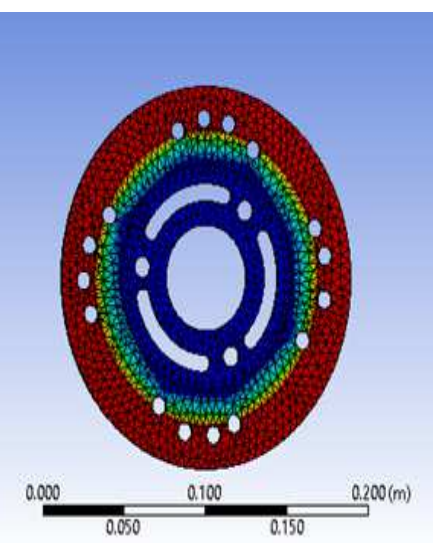

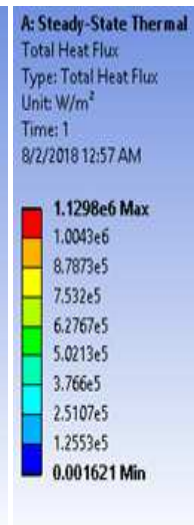

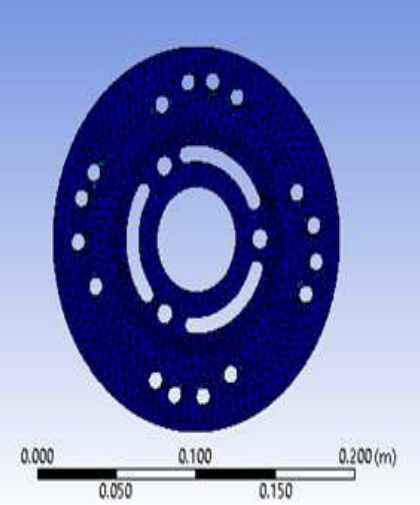

Figure 2: Thermal Analysis Done on Aluminium Alloybrake Disc 


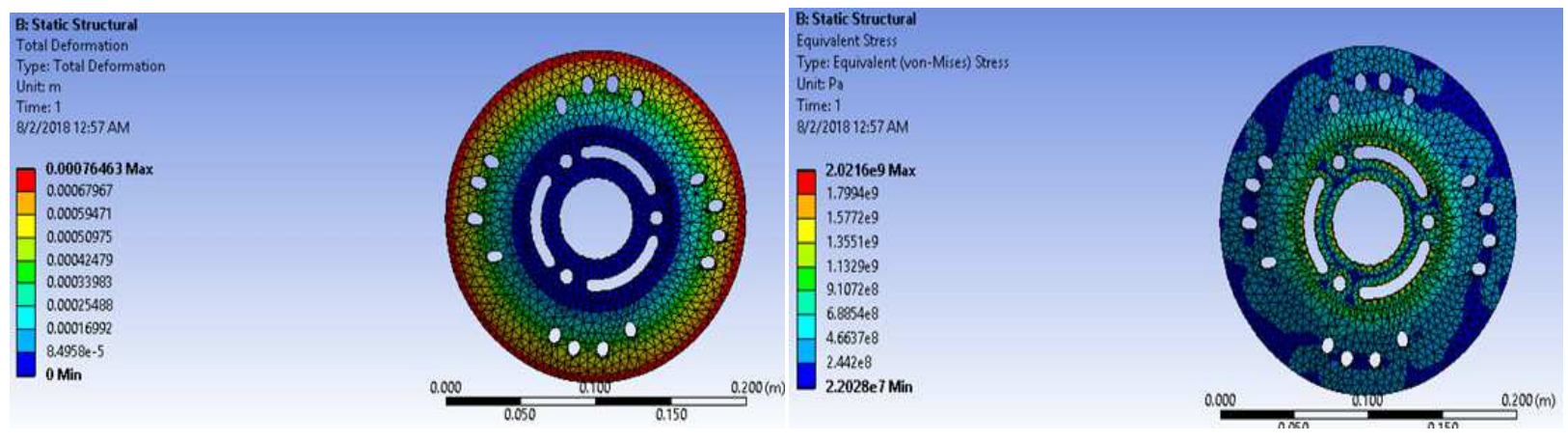

Figure 3: Structural Analysis Done on Aluminium Alloybrake Disc

Case 2:- Stainless Steel Brake Disc
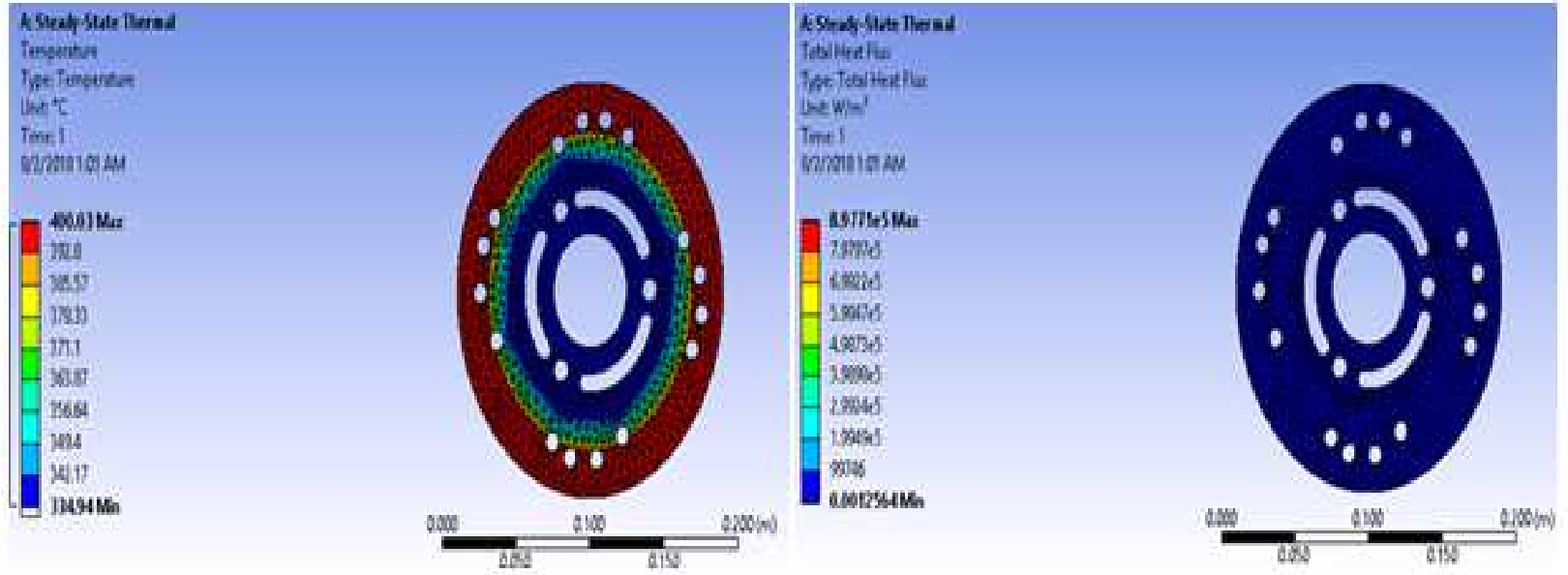

Figure 4: Thermal Analysis Done on Stainless Steel Brake Disc

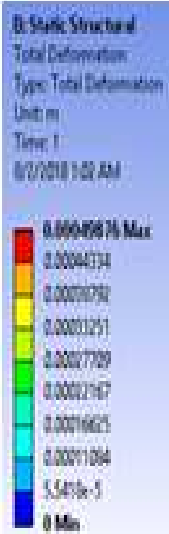
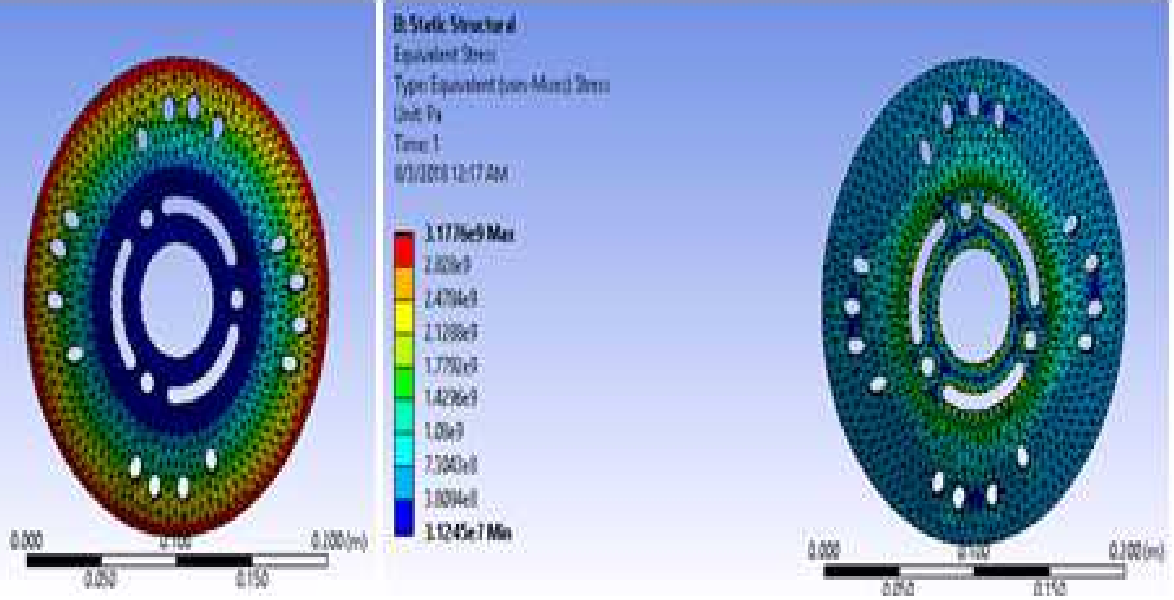

Figure 5: Structural Analysis Done on Stainless Steel Brake Disc 


\section{Case 3: Gray castironbrake Disc}

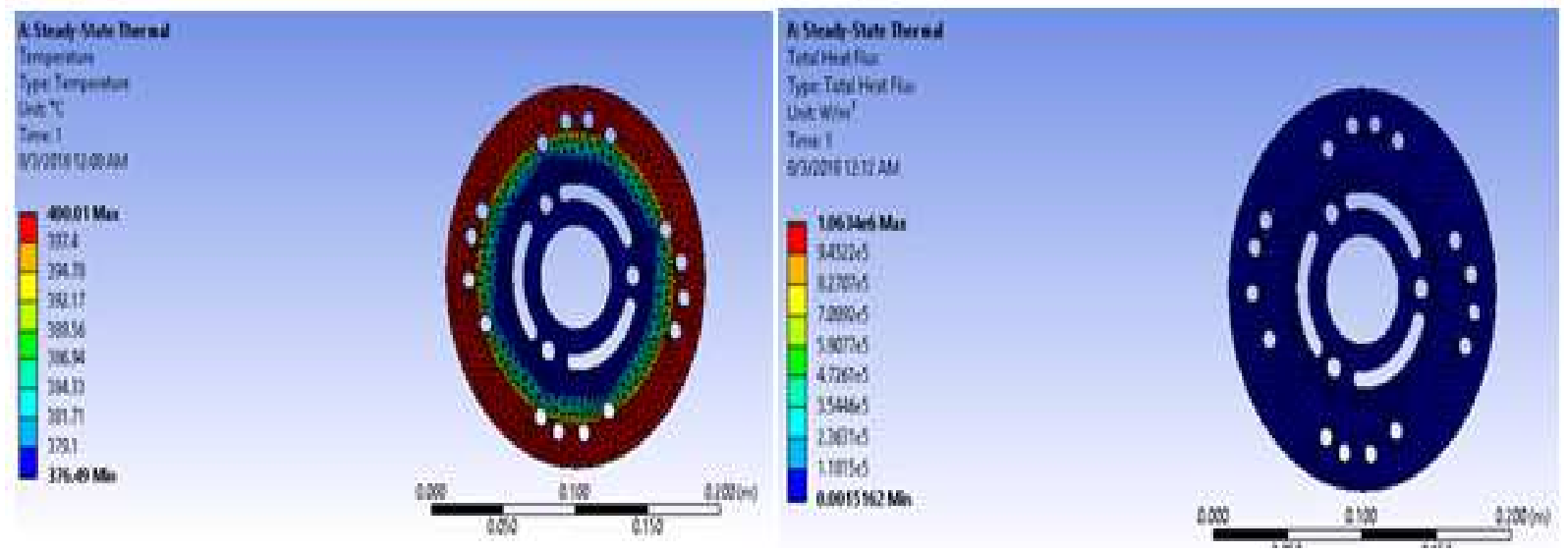

Figure 6: Thermal Analysis Done on Gray Castiron Brake Disc
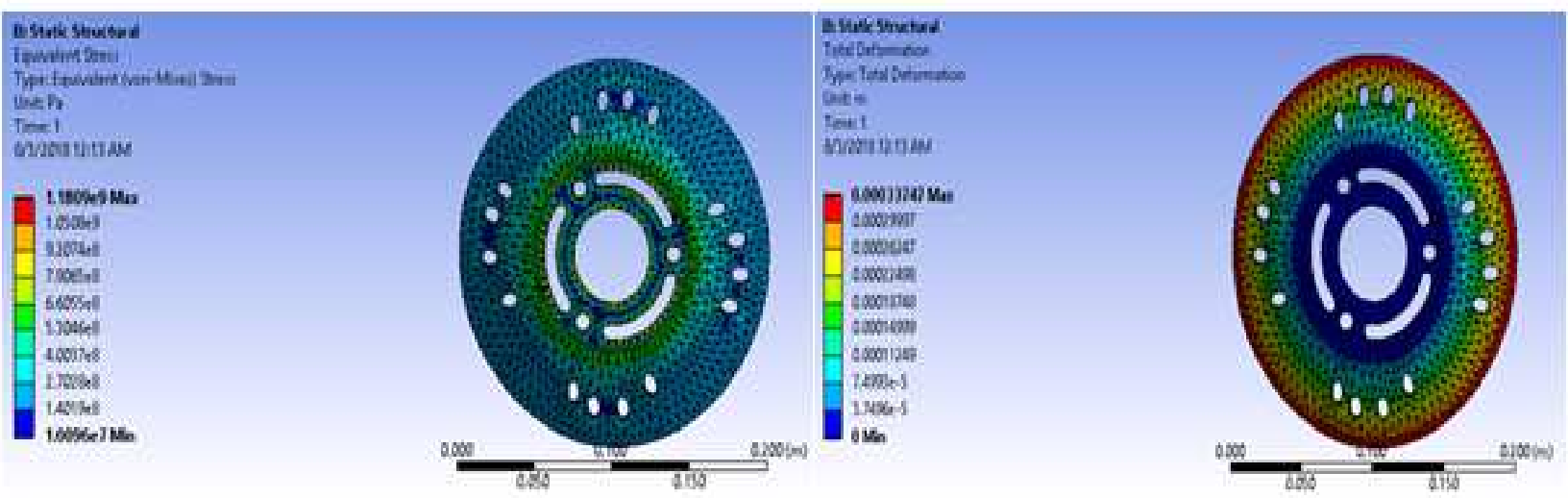

Figure 7: Structural Analysis Done on Gray Castiron Brake Disc

According to the thermal and structural analysis done with the help of ansys on the brake discs of different materials, the resulted values of different parameters are show below in the table.

Table 2: Resulted Values of Different Parameters After the Analysis

\begin{tabular}{|l|c|c|c|c|}
\hline \multicolumn{1}{|c|}{ Materialused } & $\begin{array}{c}\text { Minimum } \\
\text { Temperature }\end{array}$ & $\begin{array}{c}\text { Maximum } \\
\text { Deformation(mm) }\end{array}$ & $\begin{array}{c}\text { Maximum Equivalent } \\
\text { Stress }(\mathbf{P a})\end{array}$ & $\begin{array}{c}\text { Maximum Heat Flux } \\
\left(\mathbf{w} / \mathbf{m}^{\wedge} \mathbf{2}\right)\end{array}$ \\
\hline Aluminium alloy & $392^{\circ} \mathrm{C}$ & 0.76 & $2.0216 \mathrm{e} 9$ & $1.1298 \mathrm{e} 6$ \\
\hline Gray castiron & $376.49^{\circ} \mathrm{C}$ & 0.337 & $1.1809 \mathrm{e} 9$ & $8.9771 \mathrm{e} 5$ \\
\hline Stainlesssteel & $334.94^{\circ} \mathrm{C}$ & 0.0498 & $3.0776 \mathrm{e} 9$ & $1.0634 \mathrm{e} 6$ \\
\hline
\end{tabular}

\section{CONCLUSIONS}

After doing the structural an thermal analysis on brake disc of different material with the help of software like ansys and solid works, we have got some results which is shown in table.2 considering the results, we can choose the best material which can give the better efficiency and which have better life. According to the results, the minimum deformation is occurring in gray cast iron brake disc but at the same point it is having the higher temperature of $376.49^{\circ} \mathrm{c}$ which means that it is unable to dissipate the heat which can properly decrease tool life and increase tool wear. Aluminum alloy is having maximum deformation of $0.76 \mathrm{~mm}$ and the temperature is $392^{\circ} \mathrm{c}$ which can be a negative point as we have the better options. Finally, we have stainless steel which has the minimum temperature of $334.94^{\circ} \mathrm{c}$ and maximum 
deformation of $0.0498 \mathrm{~mm}$ which is very less. It also has a good value of resulted heat flux so it can dissipate heat very efficiently which can increase tool life and tool wear.

Comparing all the resulted parameters, advantages and disadvantages, we can conclude that stainless steel is the material which can give better efficiency to the brake disc.

\section{REFERENCES}

1. Amrish PN (2016) Computer Aided Design and Analysis of Disc Brake Rotors. AdvAutomob Eng 5: 144. doi:10.4172/21677670.1000144

2. Belhocine, Ali, and Mostefa Bouchetara. "Structural and Thermal Analysis of Automotive Disc Brake Rotor." Archive of Mechanical Engineering, vol. 61, no. 1, 2014, pp. 89-113., doi:10.2478/meceng-2014-0005.

3. Medonos, S. "Study of Structural Behaviour of VentilatedBrake Disc." SAE Technical Paper Series, 1983, doi:10.4271/831316.

4. "Thermo-Structural Analysis of Disc Brake for Maximum Heat Dissipation." March 2017 Singapore International Conferences, 2017, doi:10.17758/eap.u0317107.

5. G. Babukanth and M. Vimal Teja "TransientAnalysis of Disk Brake By usingAnsys Software" International Journal of Mechanical and Industrial Engineering (IJMIE), ISSN No. 2231 -6477, Vol-2, Issue-1, 2012. 